\title{
Cocoa Extract
}

National Cancer Institute

\section{Source}

National Cancer Institute. Cocoa Extract. NCI Thesaurus. Code C121851.

A dietary supplement containing cocoa extract derived from the cacao bean, with potential vasodilating, anti-inflammatory, cardiovascular protective, neuroprotective, cognition enhancing and chemopreventive activities. Cocoa extract contains flavonoids, including high levels of epicatechin, catechin, procyanidins and xanthines, such as theobromine. Upon oral administration, the bioactive ing redients in the cocoa extract inhibit angiotensin-converting enzyme (ACE) and increase the production of nitric oxide (NO) through the activation of endothelial nitric oxide synthase (eNOS). This causes vasodilation, improves blood flow, and decreases blood pressure. The cocoa extract also improves insulin sensitivity, enhances cognition, and decreases the production of proinflammatory molecules. In addition, this extract exerts antioxidant effects and is able to scavenge reactive oxygen species (ROS). As a result, healthy cells are protected from oxidative stress and DNA damage. 